\title{
Towards Ethics in Robotic Cities
}

Yosoph Hassan Othman Sindi

Mullard Space Science Laboratory

University Collage London

London, United Kingdom ucasysi@ucl.ac.uk

\author{
Dr Raul Leal Ascencio \\ Mullard Space Science Laboratory \\ University Collage London \\ London, United Kingdom \\ r.leal@ucl.ac.uk
}

\author{
Dr Michael Emes \\ Mullard Space Science Laboratory \\ University Collage London \\ London, United Kingdom \\ m.emes@ucl.ac.uk
}

\begin{abstract}
A new concept has emerged from the Internet of Things (IoT) called the Internet of Robotic Things (IoRT). Within urban environments, decisions concerning our habitat are commonly made via democratically or by consensus. Future systems involving IoT and IoRT will include, not only hard elements, but also software, (such as bots) and social to soft system interactions, with many stakeholders resulting in ambiguity and unclear requirements. In the case of wicked problems, this research looks into the area of knowledge cocreation and Problem Structuring Methods (PSM), which work better. In the near future, we will be surrounded by a large number of software and hardware systems that uses collaborative AI, or at least co-dependent AI. Similar to the science of human to computer interaction, we will have distributed social systems to distributed AI interaction. This research sheds light on ethics as a socio-technical element when modelling robotic cities infrastructures. The paper considers full actuation autonomy and control by IoT/IoRT, therefore adding software bots and social soft systems into the mix, as well as interdependencies of infrastructure hard-systems. Past robotics research of ethics debates whether ethics should be taught to robots vs hard programmed into robots, whilst a third school of thought discusses the philosophical implications. This research takes an alternative route to that. It provides definitions, establishes common grounds and opens discussions regarding how we can model our societies' interactions with a distributed Artificial Intelligent (AI) system; replacing the various human experts running the autonomous city. The research concludes with a preliminary proposal that is an abstraction resulted from a literature review conducted in this topic area.
\end{abstract}

Keywords-AI safety Engineering, BIM3, IoRT, prosumers, robotic cities, socio-technical, techno-social, wicked problems.

\section{INTRODUCTION}

A large part of research related to ethics in robotics tends to be around discussing the philosophical dimensions of the matter, or studying the technical mechanisms of enabling robots to understand or work by ethical analogies [1][2][3][4]. Previous research mainly focuses on human to machine interaction. There has been very little research of the interaction between society and distributed experts (being partly or fully robotic). "Society to distributed AI/robotics systems" implies complexity of a multi-level multi-tier interdependent system. This paper introduces the concept of robotic cities, and investigates how, with complex interdependencies between soft and hard systems, experts can utilize powerful tools to achieve potentially better solutions to wicked problems.

The methodology conducted is grounded theory methodology and the topic of ethics was selected because it has a philosophical dimension where past research attempted a computational engine (i.e. robot) envisaging it. Therefore, creating a bridge that paves the way on how distributed robotics can handle non-optimizable wicked problems.
In 2012, a new terminology was coined known as 'Smart Cities' [5]. There is no globally agreed definition for Smart Cities [6]. Various cities have selected goals to be achieved over a duration of time; as a means of defining what type of Smart Cities they want to become [7].

Robots are becoming increasingly involved in our daily lives: dishwashers, washing machines, fly-by-wire aeroplanes, and many more machines have become part of what defines our era. The Oxford English Dictionary definition for "Robot" states the word 'Automatically' and not 'autonomously'. This leads to the following definitions [8]:

- $\quad$ Automated: Made to be automatic

- Autonomous: Involves self-governance, implies satisfactory performance under significant uncertainties in the environment and the ability to compensate for system failures without external intervention

A new term was coined in 2013: "AI Safety Engineering" [9] It is based on Hanson's analogy that there is no need for highly ethical robot agents, whilst they are not superior to humans, we only need them to be safe and law-abiding [10]. Even by following this approach, challenges may arise that can have a contextual or universal ethics implication (difference will be elaborated at later stage in this paper).

For a robot to be ethical, it has to have [1]:

- Complete ability to predict the consequences of its own actions (or inactions),

- A set of ethical rules against which to test each possible action/consequence, so it can select the most ethical action,

- Legal authority to carry-out autonomous decision making and action, accompanied by associated liability

Yet, ethics here still has several levels of morality [11]:

- Operational morality (moral responsibility lies entirely in the robot designer and user).

- Functional morality (the robot has the ability to make moral judgments without top-down instructions from humans, and the robot designers can no longer predict the robot's actions and their consequences).

- Full morality (the robot is so intelligent that it decides on its action; thereby being fully responsible for them).

This research considers the autonomy of Smart Cities infrastructures as a heterogeneous distributed robotic system. Considering the latest version and standards of Building Information Management (BIM3), the research also considers inhabitants' welfare, other social factors, sustainability and 
socio-technical prosperity [12]. Research conducted at MIT media lab also points out that cities of the future will not only be smart but will involve many moving components of all sizes and shapes that have full autonomy and/or tele-operation [13].

The research contribution is to present the preliminary hypotheses that aims to provide a better approach in achieving ethical robotic cities. That is: in the area of Ethics a similar way of how PSM works best for wicked problems, it could be a good starting point to have Distributed AI co-create solutions with the social infrastructure of future cities.

\section{SCOPE}

This is the first part of a wider research project related to robotic cities. This part focuses on introducing the foundations of the new methodology, concepts and related tools that will be used in the upcoming work. Further research is planned to analyze the results and show indications of how to better integrate these tools with urban environments' modelling methodologies. Therefore, this research opens the discussions for the complexities that cities will face during their journeys from their current status to smart, followed by fully autonomous robotic cities.

\section{FOUNDATIONS}

The following considerations form the key underpinning principles for this research:

1) Sustainability and resilience problems are naturally 'super-wicked' problems [14].

2) Policies have become more interdependent with infrastructures when tackling wicked problems [15],

3) The use of PSM and co-creation for decisions related to wicked problems provide solutions with wider acceptance [15].

4) Figure (1) illustrates how inhabitants' economic systems interact with social, environmental and infrastructure systems [16].

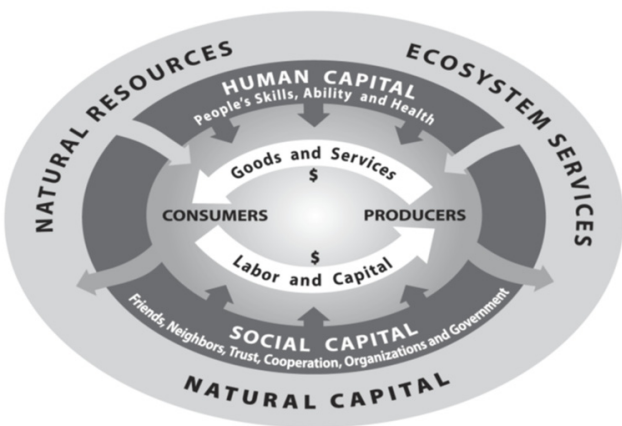

Fig. 1. M. Hart, Sustainable Measures (C)

5) Consideration of the inhabitants' techno-social status as the infrastructure, instead of the physical infrastructures, such as electricity grids, buildings and transportation. [17].

The points above help create a starting point for establishing an alternative methodology for the proposed ethical approach in building large distributed autonomous robotic systems that work closely with human urban habitat, socio-technical structures and environments.

All smart city projects head towards some sort of infrastructure automation or autonomy. This is done by adapting intelligent data analytics and remote control/management capabilities. This leads to a new paradigm where the city is viewed as a heterogeneous distributed robot. This view becomes more obvious when comparing established cities in their journey towards transformation into smart cities, and cities built as smart from the ground-up.

\section{WHAT ARE ROBOTIC CITIES?}

The Society of Automotive Engineers (SAE) have introduced and tabulated five-level tier standard for driving automation for on-road vehicles. A simplification of their table is presented below [18].

TABLE I. FIVE-LEVEL TEAR STANDARD FOR DRIVING AUTOMATION FOR ON-ROAD VEHICLES

\begin{tabular}{|c|c|c|}
\hline Level & Name & Narrative Definition \\
\hline 0 & $\begin{array}{c}\text { No } \\
\text { Automation }\end{array}$ & $\begin{array}{l}\text { The full-time performance by the human driver } \\
\text { off all aspects of the dynamic driving task, even } \\
\text { when enhanced by warning or intervention. }\end{array}$ \\
\hline 1 & $\begin{array}{c}\text { Driver } \\
\text { Assistance }\end{array}$ & $\begin{array}{l}\text { The driving mode-specific execution by a driver } \\
\text { assistance system of either steering or } \\
\text { acceleration/deceleration using information } \\
\text { about the driving environment and with the } \\
\text { expectation that the human driver performs all } \\
\text { remaining aspects of the dynamic driving tasks }\end{array}$ \\
\hline 2 & $\begin{array}{c}\text { Partial } \\
\text { Automation }\end{array}$ & $\begin{array}{l}\text { The driving mode-specific execution by one or } \\
\text { more driver assistance systems of both steering } \\
\text { and acceleration/deceleration using information } \\
\text { about the driving environment and with the } \\
\text { expectation that the human driver performs all } \\
\text { remaining aspects of the dynamic driving tasks }\end{array}$ \\
\hline 3 & $\begin{array}{l}\text { Conditional } \\
\text { Automation }\end{array}$ & $\begin{array}{l}\text { The driving mode-specific performance by an } \\
\text { automated driving system of all aspects of the } \\
\text { dynamic driving task with the expectation that } \\
\text { the human driver will respond appropriately to a } \\
\text { request to intervene }\end{array}$ \\
\hline 4 & $\begin{array}{c}\text { High } \\
\text { Automation }\end{array}$ & $\begin{array}{l}\text { The driving mode-specific performance by an } \\
\text { automated driving system of all aspects of the } \\
\text { dynamic driving task even if human driver does } \\
\text { not respond appropriately to a request to } \\
\text { intervene }\end{array}$ \\
\hline 5 & $\begin{array}{l}\text { Full } \\
\text { Automation }\end{array}$ & $\begin{array}{l}\text { The full-time performance by an automated } \\
\text { driving system of all aspects of the dynamic } \\
\text { driving task under all roadway and } \\
\text { environmental conditions that can be managed } \\
\text { by a human driver }\end{array}$ \\
\hline
\end{tabular}

A software bot is: "A program that runs autonomously and performs repetitive and/or remotely-controlled tasks, from very simple commands to complex manipulations" [19]. A valid consideration would be that if several IoT devices are connected to internet bots, does that make them a distributed robotic system?

The answer is that it is a centralised system unless it is connected to more than one bot, and most importantly, triggers actuation.

Examples of some cities with existing robotic infrastructures would be the Masdar City's Personal Rapid Transit (PRT) and electricity grid, along with South Korea's Songo Waste Management system. From the examples and definitions provided, a similar table can be devised to define 
the level of robotic cities' autonomy. As per table (I), table (II) has been created. The concept of robotic cities is not new, in fact since the early 1960s, Ron Herron (a Professor of Radical Architecture) has delivered an inception of a robotic city called "Walking City" that delivered the inhabitants from their homes to their places of work and vice versa [20].

TABLE II. FIVE-LEVEL TEAR EXPLANATION FOR CITY AUTOMATION

\begin{tabular}{|c|c|c|c|}
\hline Level & Name & Narrative Definition & $\begin{array}{c}\text { Morality } \\
\text { level }\end{array}$ \\
\hline 0 & $\begin{array}{c}\text { No } \\
\text { Automation }\end{array}$ & $\begin{array}{l}\text { The full-time performance by } \\
\text { the human labor to all aspects } \\
\text { of the city from planning to } \\
\text { managing and maintenance }\end{array}$ & Operational \\
\hline 1 & $\begin{array}{c}\text { Smart } \\
\text { Assistance }\end{array}$ & $\begin{array}{l}\text { The city becomes data-driven } \\
\text { from big data feeding into } \\
\text { various sources of analysis, } \\
\text { from Geographic Information } \\
\text { Analysis (GIA) to Policy and } \\
\text { digital media social platform } \\
\text { interactions. }\end{array}$ & Operational \\
\hline 2 & $\begin{array}{c}\text { Partial } \\
\text { Automation }\end{array}$ & $\begin{array}{l}\text { Various city infrastructures } \\
\text { have partial autonomy, yet } \\
\text { human monitoring and } \\
\text { intervention may be needed in } \\
\text { difficult situations }\end{array}$ & Functional \\
\hline 3 & $\begin{array}{l}\text { Conditional } \\
\text { Automation }\end{array}$ & $\begin{array}{l}\text { Human monitoring and } \\
\text { intervention may be needed in } \\
\text { difficult situation but most of } \\
\text { the city infrastructures are } \\
\text { autonomous. }\end{array}$ & Functional \\
\hline 4 & $\begin{array}{c}\text { High } \\
\text { Automation }\end{array}$ & $\begin{array}{l}\text { Human response is there for } \\
\text { support and not critically } \\
\text { needed to manage the city } \\
\text { infrastructure. }\end{array}$ & $\begin{array}{c}\text { Full } \\
\text { morality }\end{array}$ \\
\hline 5 & $\begin{array}{l}\text { Full } \\
\text { Automation }\end{array}$ & $\begin{array}{c}\text { Urban environments can } \\
\text { autonomously regenerate or } \\
\text { expand, maintain themselves } \\
\text { and manage emergent complex } \\
\text { sustainability issues without } \\
\text { human intervention. }\end{array}$ & $\begin{array}{l}\text { Full } \\
\text { morality \& } \\
\text { considering } \\
\text { fully ethical }\end{array}$ \\
\hline
\end{tabular}

Robotic cities are a new challenge that will require a radical way of thinking, modelling and decision-making. Goyal suggests that "the 'robotic urban landscapes' could radically alter the way people live, work and play. Also, 'robotic ecology' could result in a paradigm shift in architectural discipline as it will face the needs to evolve and inform the technological and philosophical pursuits that lead to the possibility of such a machinic 'field condition' in the urban fabric of the near future" [21].

Research has shown that the concept of robotic cities is scalable. Sato has researched a robotic room that could evolve over five stages so as to have the potential scalability to a robotic city. The goal of Sato's research was to study an environmental robot system interaction within human society [22].

In this research, we are also in agreement with the concept that experts embedding technology to solve existing problems might very well not achieve a better acceptance within the wider audience, whose contribution will be needed to support growth [23]. The argument also points to the difficulties of achieving better results and holistic systems that satisfy a realistic minimum level of complexity for social factors under controlled (or laboratory) conditions. Below is a list of simplified analogies:
Driverless cars have re-triggered the ethical trolley problem [24] and its involvement in the world of robotics . Yet the trolley problem is not a quantitative question but a philosophical one. In an ideal scenario one can argue that such questions should never be resolved from a quantitative perspective regardless of what human, machine (Robot) or Cyborg is attempting it. Hence, ideally the resolution attempt must be co-created.

Policy (public/urban) is partly a quantitative question. Though the outcome will affect human inhabitants and may have an ethically debatable perspective, can this be then surrendered to an advanced computational machine (robot)?

B) better at Naturally policy design has a strong social quantitative element, and many can argue which systems are problems best suited for the different scenarios (Democratic, Consensus or PSM Co-created). As the emphasis here is related to wicked and messy problems, the focus is to bridge experts' solutions with the PSM and knowledge creation methodology [25].

In a village called Reckoning, where floods Regardless of the were a major issue, the experts' solution that expert (man or eliminated the problem was rejected by the machine), locals. After an extensive co-creation of quantitative knowledge exercise, an acceptable solution was solutions to wicked found where areas of the richer part of the problems may be community would be partly flooded in order to rejected maintain the flow of tourism and business in the village [15].

\section{IORT}

IoRT is based on Cloud Robotics and the IoT infrastructure. IoRT is defined as: "Intelligent devices that monitor events, fuse sensor data from a variety of sources, use local and distributed intelligence to determine a best course of action, and then act to control or manipulate objects the physical world, and in some cases while physically moving through that world"'[26]

Ray has explained that the architecture of IoRT is divisible into 5 layers [27]:

1) Application layer: Designed to disseminate the user experience through exploring the presented sample of applications that can be performed using robotics.

2) Infrastructure layer: Made of five but related compositions (Robotic platform support, M2M2A cloud platform, IoT Business Cloud Services, Big Data services and IoT Cloud Robotics Infrastructures)

3) Internet/Communication layer: Communication architecture, IoT specific communication protocols selectively added into this layer.

4) Network layer: Connectivity hardware and protocol such as: GSM, WiFi, Bluetooth, 6LoWPAN, Broad band, NFC, Xigbee, LAN..etc

5) The hardware/robotic things: Comprising various robots and elements such as vehicles, sensors, physical things (real-life components).

A discussion of IoRT technology maturity should consider challenges such as: Computational problems, along with Optimization and Security issues. Note that a key point for this technology maturity is that because distributed AI is part of the algorithm, all agents in the system must agree on the understanding of the task, the technical requirement and the 
solutions intended. At a city level, these require some sort of specific or general AI. Hence, it is a sine-qua-non challenge for IoRT and robotic cities that, though this technology exists, it is not ready or matured to the needed level yet. Furthermore, Ray's research considered the focal points around the users and added a section for the layer related to businesses. In this research, the understanding is that every agent that is considered as a user is also a producer of the very least one of the follow: data, actuation, policy and knowledge). Hence, all agents are "prosumers". As small and simple as this analogy is, it has a large and complex implication on modelling. This analogy alone changes the system's implied use case diagram (or user journeys'). Causal loops diagram can also highlight holistic system leverage points and help visualize how strongly or loosely coupled the system parts are. At city level, it changes the concept of IoT generating data that could potentially lead to a change in (at least) behavior or move to a strongly coupled interdependent system; where the IoRT would have physical actuation changes in the city leading to instant change in more than just behavior. It becomes clear now that the system interaction with socio-technical elements consideration is vital for a city with strong aspirations to thrive.

\section{ETHICS}

The topic of Ethics for robotic cities emphasizes the need for this research. Ethics is a deeply philosophical area with local and universal variant views that cannot be represented by numerical optimization. Taking the example of Cambridge Analytica and the USA federal law loophole for fake news [28], working towards ethical robotic cities requires us to acknowledge that we face a wicked problem. One must consider ethics of various disciplines that collectively build towards ethical robotic cities. Ethics for robotic cities are driven from: General Ethics, Ethics of Engineering, Ethics of Data Science, Ethics of Robotics, Ethics of Artificial Intelligence, Ethics of Policy and Social Science.

\section{A. General Ethics}

As per the Oxford English Dictionary, "Ethics are the moral principles that govern a person's behavior or the conducting of an activity" [29]. Ethics are divided into:

- Universal ethics, which are abstract, applicable to everyone and absolute.

- Contextual ethics, derived from local perspectives.

- Consequentialist ethics imply that "The ends justify the means.”

- Deontological ethics imply that "The means justifies the ends."

\section{B. Ethics of Engineering:}

The Royal Academy of Engineering listed twenty-six points that are sub-points to four main points [30], whilst the American Society of Civil Engineers have listed eight points [31]. Other institutes prefer to add the following points into the Engineering Code of Ethics:

- Engineers shall always honour the responsibility of protecting the environmental eco-systems.
- Engineers shall honour the duty to report ('Whistleblowing') to the appropriate authority a possible risk to others from a client or employer failing to follow the engineer's ethical directions above.

\section{Ethics of Data Science:}

As discussed earlier, big-data is a key element for all cities' infrastructures and certainly robotic cities'. It will be part of the infrastructure for almost every discipline. The term "prosumers" will be expected to replace the term "users" in many analytical areas of study within the city. Ethics of data science is therefore expected to be an additional code of ethics for each of the disciplines involved in the robotic cities. Ethics of data science will include, but not be limited to, privacy, human dignity, transparency, data-ownership, informed consent, fair, confidentiality, integrity, availability, sensitivity and criticality.

\section{What are Robot Ethics?}

Asimov wrote the first three laws of robotics and ever since it has stimulated a large philosophical debate [32], literature and multimedia sci-fi. It is commonly agreed that the three laws of robotics are not enough to have public acceptance for any of the key ethical dilemmas. Claims that it can result in revolution and overthrowing human supremacy are widely argued amongst philosophers and scientists alike. Others have suggested to add more rules [33], but they were met with the same criticism. The laws do not help us to solve famous ethics and philosophy questions, such as determining whether it is ethical to intentionally and forcibly kill one person to save another or more others (commonly known as trolley questions). Currently governments are considering regulation for AI's autonomy, such as in Germany, where the first rules for autonomous vehicles [34] have been released. Arguments about the trolley question are usually along the lines of: as a human, to be permitted to obtain a driving permit, dichotomies such as the trolley question are never part of any driving test. So why do robots need to answer such dilemmas, especially if they have better control over such complex machines? In this case, it becomes clear that as humans we are naturally born as members of the society and inherently assumed to have ethical intelligence and responsibilities, while robots are not. Subconsciously abiding to universal and contextual ethics has become the norm based on our social cohabitation, but as AI robots are starting to share the realm of human social space, and become a source of influence, the debate becomes more relevant. The matters of both Universal and Contextual Ethics are not matters of numerical optimization. Under this scenario, a more delicate question arises: if they are becoming part of the social fabric, does that imply that robots will have rights?

\section{E. Robot rights.}

It is commonly agreed that when robots are permitted to perform their functions, greater good could be gained, yet a level of risk is involved. Would this not be a trolley question in itself?

Experts argue whether specific and detailed laws will be required soon or in the distant future? The Institute for the Future and U.K. Department of Trade and Industry have by analogy linked human rights to human duties. "Robot rights" can be defined as: "the concept that people should have a 
moral obligation towards their machines, such as a right to exist and perform its own mission" [35]. This could be linked to robot duty to serve humans.

Along with what was mentioned in this section above, this indicates that Robots' basic rights are to be permitted at least to a level that allows them to perform the function they are requested to do and raise any concerns if any hindrance to the execution of the function exists. As for the mechanism by which this should be implemented, no right or wrong answer exists yet, but the involvement of the public in co-creating along with the experts is proposed by this research.

\section{F. Ethical issues in artificial intelligence:}

The World Economic Forum identified nine key ethical issues in artificial intelligence [36].

1. Robot rights: Defining the humane treatment of AI.

2. Unemployment: Defining what will happen when all jobs are gone.

3. Inequality: Distribution of the wealth created by machines.

4. Humanity: Understanding machines' and humans' effects on each other's behavior and interactions.

5. Artificial stupidity: How can we guard against mistakes?

6. Racist robots: Such as eliminating AI biases.

7. Security: How do we keep AI safe from adversaries?

8. Evil Genius: Protecting against unintended consequences.

9. Singularity: How do we stay in control of a complex intelligent system?

\section{G. What are ethical cities?}

In relation to ethical cities the United Nations have issued "Ten Principles of the UN Global Compact" [37]. They are formulated under four categories:

\section{Human Rights}

1. Businesses should support and respect the protection of internationally proclaimed human rights;

2. Make sure that they are not complicit in human rights abuses.

\section{Labor}

3. Businesses should uphold the freedom of association and the effective recognition of the right to collective bargaining;

4. The elimination of all forms of forced and compulsory labor;

5. The effective abolition of child labour; and

6. The elimination of discrimination in respect of employment and occupation.

\section{Environment}

7. Businesses should support a precautionary approach to environmental challenges;

8. Undertake initiatives to promote greater environmental responsibility;
9. Encourage the development and diffusion of environmentally friendly technologies.

\section{Anti-Corruption}

10. Businesses should work against corruption in all its forms, including extortion and bribery.

The Ten Principles of the UN Global Compact can be considered as the basic building blocks, but more is needed. As mentioned earlier, there are Universal ethics and contextual Ethics; which emphasises the need for cocreation of ethical rules in relation to the society's contextual ethics.

1. Are they enough to ensure long-term ethical sustainability?

2. What is their impact on leadership?

3. What is their impact on planning?

4. What is the impact on how the local business environment works?

5. What is the role of the individual citizen?

\section{H. What are Ethical robotic cities?}

The truthful answer to this question is that no one knows yet. But it can be observed that complex interdependent ethics of various disciplines, Universal ethics and conventions are all connected to form at least part of the robotic city ethics. Similar dilemmas to the trolley question will arise such as:

- Should electric current be redirected from homes (where some individuals could be on life-assisting equipment) to hospitals in critical need?

- Should we actively manage traffic flow, therefore affecting the distribution of wealth?

- Since Policing is robotized [38] and jury management systems are being automated [39], should robots be able to execute judgment on humans and should we have robot police?

- Should there be robots in health care? Is it ethical to have robots implementing the protocol of when to pull the plug on a life support?

\section{DISCUSSION}

Robotic cities are created by members of various disciplines. The first grounding code of ethics would be universal ethics, then contextual ethics and then followed (in equal importance) by the ethics of various disciplines. Each of the points above must be considered when working towards any distributed autonomous robotic infrastructure. Contextual ethics evolve over time and vary from one area to the other. Such planning responsibility (related to the automation) will be a new emergent ethical behavior for those involved in planning robotic cities. Numerical modelling and analysis are beneficial, but interdependencies are of the utmost importance. Since in this case the problem cannot be optimized with any numerical method or be sufficiently studied only using laboratory simulations, knowledgecocreation and PSM for handling wicked problems are as necessary as numerical modelling and simulations. Even after considering the work of Marek Rosa (founder of GoodAI), the robot is required to make mistakes so that it learns, or to be 
trained in an environment disconnected from the uncertainties and full complexity of reality [40]. This can be unethical and violates the principle that wicked problems cannot have a widely accepted solution under only laboratory tests. This brings us back to the debate relating to consequentialist ethics vs deontological ethics.

As is typical for wicked problems, the expert cannot know at first all potential outcomes from a given solution. Experts may ask at this stage, when and how, can we know the level of soft vs hard modelling prior to involving PSM and knowledge co-creation? At which stage do we initiate or stop the PSM and Knowledge co-creation with the stakeholders and users?

This research provides a proposal and paves the way for discussions into this critical problem related to robotic cities and functional/full morality systems. The proposed approach is listed below:

- The moral analogies must be coded (as in coding taxonomy) to the level of ethics spectrum needed. The spectrum ranges from "safe and law abiding" to "full morality". Interdependencies would then be identified and mapped. Experts would identify possible emergent behaviors and address them to the system stakeholders and prosumers. Based on the digital information diffusion rate [41], this research proposes the assumption that experts must consider the involvement of at least $20 \%$ of the affected endprosumers reaching them through digital platforms.

- Because such systems are large and in constant evolution, the computational element is there to help identify patterns. Evolutionary learning algorithms with exploration and exploitation are more traceable than many other AI techniques, yet they are suitable for the initial system complexity requirement. Though there exists distributed computational intelligence, it is subject to constant co-creation interference.

- For such wicked problems, confidence in predictability is not the norm. This also implies that various soft systems in the society might not be in full agreement. The more variables appear as emergent properties with high fluctuation rates, the more instability there is in the system. Hence, the general entropy theory as a measure for the system stability should be applied. A general measure of entropy provides feedback on the system stability.

There are process loops at every iteration, but they are the subject of high risk. Organizations with teams such as "Nudging Teams" could manipulate prosumer opinions. The control loop diagram below visualizes the proposed approach.

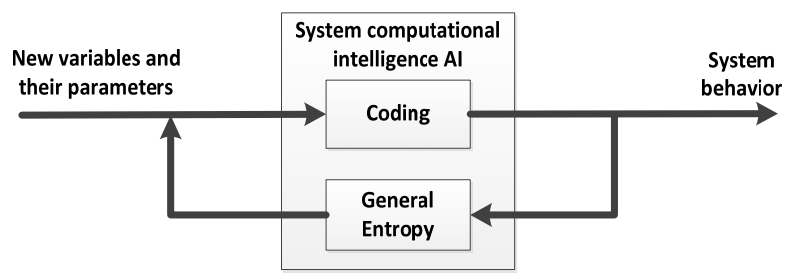

Fig. 2. Proposed methodology visualization

Modelling problems related to city infrastructure can commonly be more complex than the travelling-salesman problem, making them at least at NP-Hard level of complexity. Because our focus is related to socio-technical problem they become wicked problems. Based on research in support of using PSM for approaching wicked problems [14], AI can take part resembling the experts of the system (or in support of the experts). As wicked problems have no definitive solution but the system can be better or worse, the proposed measure here is general system entropy. This in turn indicates better support that AI could be part of a PSM and cocreated solutions system. On the wider global system of cities, it is inevitable that humans have biases (positive or negative); this highlights a risk area of using such systems where agents can be influenced by organized campaigns. Though this risk exists in both democratic and consensus systems, the fact that AI agents are a new introduction to society would trigger a wider debate on ethics. This must be fairly addressed using the aspects of ethics explained earlier in this research.

\section{CONCLUSION}

To conclude, it can be said that to have an ethical robotic city, it is not only a complex NP-hard numerical problem that needs optimization, it is a soft and hard system engineering problem that is also a wicked problem. Although AI is best at finding optimal solutions as the problem evolves over time, it is not the sole tool for addressing this problem. A combination of multiple tools implemented methodologically and with careful ethical monitoring should take place. This is the first part of a series of publications and it represents an understanding of our path towards robotic cities. Furthermore, it has presented a roadmap that aims to help experts towards ethical robotic cities.

Future work will be related to the modelling of interdependencies and how can such systems be better represented. It is only after such concepts are grounded, that we can then build upon new approaches for analyzing behaviors of such systems in future robotic cities.

\section{REFERENCES}

[1] S. G. Tzafestas, "Ethics in Robotics and Automation: A General View," vol. 4, no. 3, pp. 229-234, 2018.

[2] R. C. Arkin, "Governing Lethal Behavior: Embedding Ethics in a Hybrid Deliberative/Reactive Robot Architecture Part I: Motivation And Philosophy," Proc. 3rd Int. Conf. Hum. Robot Interact. - HRI '08, p. 121, 2008.

[3] G. Veruggio and F. Operto, "Roboethics: a bottom-up interdisciplinary discourse in the field of applied ethics in robotics," Int. Rev. Inf. ethics, vol. 6, no. 12, pp. 2-8, 2006. B. Ingram, D. Jones, A. Lewis, M. Richards, C. Rich, and L. Schachterle, "A code of ethics for robotics engineers," in Proceedings of the 5th ACM/IEEE International Conference on Human-robot Interaction, 2010, pp. 103-104.

[5] H. Schaffers, N. Komninos, and M. Pallot, "Smart cities as innovation ecosystems sustained by the future internet," FIREBALL White Pap. EU, 2012.

[6] D. McLaren and J. Agyeman, Sharing cities: a case for truly smart and sustainable cities. MIT Press, 2015.

"The Top 10 Smart Cities On The Planet." [Online]. Available: https://www.fastcompany.com/90186037/the-top-10-smart-citieson-the-planet. [Accessed: 20-Aug-2018].

[8] P. J. Antsaklis, K. M. Passino, and S. J. Wang, "An introduction to autonomous control systems," IEEE Control Syst., 1991. R. V. Yampolskiy, "Artificial intelligence safety engineering: Why machine ethics is a wrong approach," in Studies in Applied Philosophy, Epistemology and Rational Ethics, 2013.

[10] R. Hanson, "Prefer Law To Values," Overcoming Bias (blog). 2009.

[11] W. Wallach and C. Allen, Moral Machines: Teaching Robots 
Right from Wrong. 2009.

[12] H. Shayesteh, "Digital Built Britain Level 3 Building Information Modelling Strategic Plan,” 2015.

[13] K. Larson, "Kent Larson: Brilliant designs to fit more people in every city | TED Talk," TEDxBoston, 2012. [Online]. Available: https://www.ted.com/talks/kent_larson_brilliant_designs_to_fit_ more_people_in_every_city. [Accessed: 23-Jun-2018].

[14] M. Yearworth, "Sustainability as a 'super-wicked' problem; opportunities and limits for engineering methodology," Intell. Build. Int., vol. 8, no. 1, pp. 37-47, 2016.

[15] S. N. Lane, N. Odoni, C. Landström, S. J. Whatmore, N. Ward, and S. Bradley, "Doing flood risk science differently: An experiment in radical scientific method," Trans. Inst. Br. Geogr., vol. 36 , no. 1, pp. 15-36, 2011

[16] R. Costanza, M. Hart, S. Posner, and J. Talberth, "Beyond GDP: The Need for New Measures of Progress," Trans. Inst. Br. Geogr., vol. 36, no. 1, pp. 15-36, 2009.

[17] B. Frischmann and E. Selinger, Re-engineering humanity. Cambridge University Press, 2018.

[18] S. A. E. International, "Automated driving: levels of driving automation are defined in new SAE international standard J3016," 2014.

[19] K. Dunham and J. Melnick, Malicious bots: an inside look into the cyber-criminal underground of the internet. Auerbach Publications, 2008.

[20] P. Wilkinson, Phantom Architecture. New York: Simon \& Schuster UK, 2017.

[21] A. Goyal, "Field Condition and the Robotic Urban Landscapes."

[22] T. Sato, "Robotic room: Human behavior measurement, behavior accumulation and personal/behavioral adaptation by intelligent environment," IEEE/ASME Int. Conf. Adv. Intell. Mechatronics, $A I M$, vol. 1, no. Aim, pp. 515-520, 2003.

[23] H. W. J. Rittel and M. M. Webber, "Dilemmas in a general theory of planning," Policy Sci., vol. 4, no. 2, pp. 155-169, 1973.

[24] D. (Princeton U. Edmonds, Would you kill the fat man?: The trolley problem and what your answer tells us about right and wrong. 2013.

[25] A. I. Woody, "Political Justification through Democratic Participation: The Case for Conscientious Objection," vol. 41, no. Kitcher 1989, pp. 1-35, 2015.

[26] "The Internet of Robotic Things | ABI Research," 2014. [Online]. Available: https://www.abiresearch.com/marketresearch/product/1019712-the-internet-of-robotic-things/. [Accessed: 20-Aug-2018].

[27] P. P. Ray, "Internet of Robotic Things: Concept, Technologies, and Challenges," IEEE Access, vol. 4, pp. 9489-9500, 2016

[28] M. Rosenberg, N. Confessore, and C. Cadwalladr, "How Trump consultants exploited the Facebook data of millions," New York Times, vol. 17, 2018.

[29] "ethics | Definition of ethics in English by Oxford Dictionaries," Oxford Dictionay. [Online]. Available:

https://en.oxforddictionaries.com/definition/ethics. [Accessed: 20-Aug-2018].

[30] "Engineering ethics - Royal Academy of Engineering." [Online]. Available: https://www.raeng.org.uk/policy/engineeringethics/ethics. [Accessed: 20-Aug-2018].

[31] "Code of Ethics | ASCE." [Online]. Available: http://www.asce.org/code-of-ethics/. [Accessed: 20-Aug-2018].

[32] I. Asimov, I, robot, vol. 1. Spectra, 2004.

[33] H. Hamann, "Short Introduction to Robotics," in Swarm Robotics: A Formal Approach, Springer, 2018, pp. 33-55.

[34] VDA, "Automotive industry welcomes new legal framework for automated driving - VDA," 2017. [Online]. Available: https://www.vda.de/en/press/press-releases/20170512automotive-industry-welcomes-new-legal-framework-forautomated-driving.html. [Accessed: 20-Aug-2018].

[35] "BBC NEWS | Technology | Robots could demand legal rights," 2006. [Online]. Available: http://news.bbc.co.uk/1/hi/technology/6200005.stm. [Accessed: 20-Aug-2018].

[36] J. Bossmann, "Top 9 ethical issues in artificial intelligence | World Economic Forum," 2016. [Online]. Available: https://www.weforum.org/agenda/2016/10/top-10-ethical-issuesin-artificial-intelligence/. [Accessed: 20-Aug-2018].

[37] "Locking in Liveability Disclaimer," 2016. [Online]. Available: https://www.wvi.org/sites/default/files/Ethical Cities UTC Final Report (UNHabitat)_1.pdf. [Accessed: 20-Aug-2018].
[38] E. E. Joh, "Policing police robots," UCLA L. Rev. Discourse, vol. 64, p. 516, 2016.

[39] R. T. Shepard, "Jury Trials Aren't What They Used to Be," Ind. L. Rev., vol. 38, p. 859, 2005.

[40] S. Parkin, "Teaching robots right from wrong," The Economist, London, Jul-2017.

[41] L. Loh and N. Venkatraman, "Diffusion of information technology outsourcing: influence sources and the Kodak effect," Inf. Syst. Res., vol. 3, no. 4, pp. 334-358, 1992. 